B.В.Войцеховский, Ю.С.Ландышев, А.А.Григоренко

\title{
Морфо-функциональное состояние бронхолегочной системы у больных множественной миеломой
}

ГОУ ВПО "Амурская государственная медицинская академия Минздравсоцразвития РФ": 675000, Благовещенск, ул. Горького, 95

\section{V.V.Voytsekhovsky, Yu.S.Landyshev, A.A.Grigorenko \\ Morphological and functional features of bronchopulmonary system in patients with multiple myeloma}

\begin{abstract}
Summary
The aim of this research was to study morphological and functional status of patients with multiple myeloma (MM). One hundred and three patients were investigated. Paraproteinosis (58\%), pulmonary sclerosis (78.5\%), pulmonary emphysema (78.5\%), amyloidosis (13.8\%), pulmonary edema, uremic pneumonitis, and calcinosis were revealed in patient with renal insufficiency. Patients with advanced MM had diminished diaphragm excursion both in tidal and forced breathing due to myelomatous pleural lesion and destruction of the chest skeleton. Restrictive and mixed restrictive and obstructive ventilatory disorders were found in patients with MM IIIA stage caused by destruction of the chest flat bones and specific myelomatous and uremic lesions of the lungs. Hypoxemia and pulmonary hypertension were revealed in $52 \%$ of patients with advances disease. Increased blood viscosity and anemia in patients with advanced disease led to endobronchial blood circulation disorders.

Key words: multiple myeloma, bronchopulmonary system.
\end{abstract}

\section{Резюме}

Целью исследования явилось изучение морфо-функционального состояния бронхолегочной системы у больных множественной миеломой (ММ) на разных этапах опухолевой прогрессии. Комплексно были обследованы 103 пациента с ММ. При проведении морфологического исследования легких, бронхов, плевры 65 умерших от ММ установлено, что патоморфологическими проявлениями миеломатозного поражения бронхолегочной системы являются парапротеиноз легких (58 \%), специфическая плазмоклеточная и лимфоидная инфильтрация легких и бронхов (40 \%), пневмосклероз (78,5\%), эмфизема легких (78,5\%), амилоидоз (13,8 \%), миеломатозное поражение плевры (6,5\%), при развитии почечной недостаточности - нефрогенный отек легких (80\%), уремический пневмонит (28\%), кальциноз (25\%). У больных ММ на поздних этапах опухолевой прогрессии отмечается значительное снижение экскурсии диафрагмы при спокойном и форсированном дыхании вследствие ее миеломатозного поражения и остеодеструктивного процесса в грудной клетке. У пациентов с IIIA стадией ММ и при присоединении хронической почечной недостаточности вследствие развития остеодеструктивного процесса в плоских костях грудной клетки, специфического миеломатозного и уремического поражения бронхолегочной системы, нарушения экскурсии диафрагмы, при проведении спирографии, диагностировано нарушение вентиляционной функции легких по рестриктивному и смешанному типам. У 52 \% больных ММ на поздних этапах опухолевой прогрессии диагностированы гипоксемия и легочная гипертензия. При проведении энодобронхиальной лазерной допплеровской флоуметрии установлено, что в процессе опухолевой прогрессии при ММ вследствие повышенной вязкости крови и анемического синдрома нарушаются показатели эндобронхиальной микрогемоциркуляции.

Ключевые слова: множественная миелома, бронхолегочная система.

Множественная миелома (ММ) - злокачественное лимфопролиферативное заболевание, характеризующееся инфильтрацией костного мозга плазматическими клетками, наличием моноклонального иммуноглобулина в сыворотке крови и / или моче и остеолитическими поражениями костей [1]. На фоне современной терапии продолжительность жизни больных ММ постоянно увеличивается [2-4]. В то же время успех в лечении этих пациентов часто определяется возможностями профилактики и лечения инфекционных осложнений, прежде всего со стороны бронхолегочной системы. Среди инфекционных осложнений ММ диагностируются острый бронхит, пневмония, постпневмонический абсцесс [5, 6]. Лейкемические поражения дыхательной системы у больных ММ достаточно изучены. Склонность к возникновению респираторных инфекций объясняется выраженным вторичным иммунодефицитом (в первую очередь, гипоиммуноглобулинемией), нейтропенией, проводимой химиотерапией, специфическими бронхолегочными проявлениями ММ - лимфоидной и плазмоклеточной инфильтрацией, парапротеинозом легких, амилоидозом, локализацией миеломных узлов в ребрах, ткани легких и бронхов [6-8].

Целью данного исследования явилось изучение особенностей нарушения вентиляционной функции легких, эндобронхиальной микрогемоциркуляции, морфологических и функциональных изменений диафрагмы на разных этапах опухолевой прогрессии MM, способствующих возникновению, тяжелому и затяжному течению бронхолегочных инфекций.

\section{Материалы и методы}

Были обследованы 103 пациента с ММ без сопутствующих бронхолегочных заболеваний и не злоупотребляющих курением, и 30 здоровых людей, соответствующих по полу и возрасту больным ММ (контрольная группа). Больные ММ были разделены на 3 группы в соответствии с классификацией B.Durie и S.Salmon [9]. В 1-ю группу вошли 38 больных ММ 
в стадиях IА и IIA (средний возраст $-56,0 \pm 4,6$ года), во 2-ю - 42 пациента в стадии IIIA (средний возраст $58,0 \pm 6,5$ года), в 3-ю - 23 больных в стадии ІІІБ (с наличием хронической почечной недостаточности - ХПН; средний возраст $57 \pm 6,6$ лет).

Функцию внешнего дыхания (ФВД) оценивали на спирографе Fukuda (Япония). Диагностическая фибробронхоскопия (ФБС) проводилась с помощью фибробронхоскопа Olympus (Япония). Эндобронхиальная лазерная допплеровская флоуметрия (ЛДФ) выполнялась посредством лазерного анализатора капиллярного кровотока "ЛАКК-02" ("Лазма", Россия). После визуального осмотра бронхиального дерева световодный зонд прибора с длиной волны лазерного излучения 0,63 мкм проводили через биопсийный канал фибробронхоскопа и под контролем зрения устанавливали на слизистой оболочке на 1,5 см дистальнее шпоры правого верхнедолевого бронха (рисунок). Допплерограммы записывали в течение 3 мин при помощи прикладной компьютерной программы (LDF, версия 2.20.0 507WL). Оценивали следующие показатели: параметр микрогемоциркуляции (ПМ), среднее квадратичное отклонение ПМ $(\sigma)$, коэффициент вариации $(\mathrm{Kv})$, амплитуды колебаний ( $\mathrm{A}_{\ni}-$ в эндотелиальном, $\mathrm{A}_{\mathrm{H}}-$ в нейрогенном, $\mathrm{A}_{\mathrm{M}}-$ в миогенном, $\mathrm{A}_{д}-$ в дыхательном, $\mathrm{A}_{\mathrm{c}}$ - в сердечном диапазонах), рассчитываемые с помощью непрерывного Вейвлет-преобразования [10].

Ультразвуковое исследование сердца и диафрагмы проводили на аппаратах Shimadzu SDU 500 A и Aloka 650SSD (Япония). Среднее давление в легочной apтерии (ДЛА ke et al. Нормой показателя ДЛА ср считали 9-16 мм рт. ст., о легочной гипертензии судили при повышении ДЛА Функциональное состояние диафрагмы исследовали по методу О.Н.Сивяковой и О.А.Мажаровой [12]. Кислотно-щелочное состояние и газовый состав крови определяли при помощи автоматического газового анализатора EasyStat (США).

После аутопсии проведено гистологическое исследование легких, сегментарных бронхов, плевры, диафрагмы 65 пациентов, умерших от ММ.

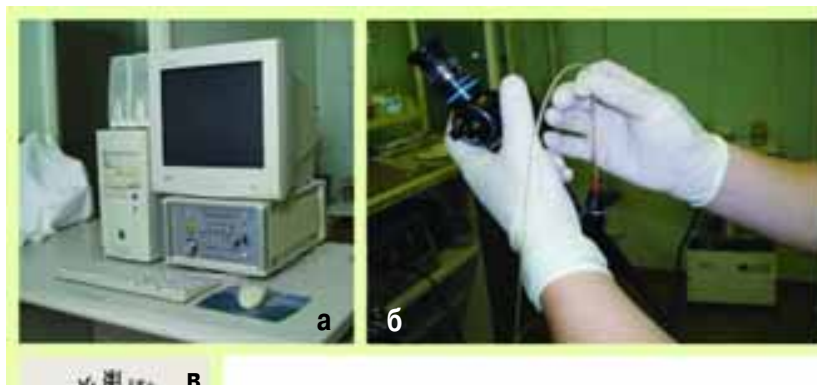

Рисунок. Лазерная допплеровская флоуметрия: а - лазерный анализатор капиллярного кровотока ЛАКК-02 ("Лазма", Россия); б - введение световода в биопсийный канал фибробронхоскопа; в, г - установка световода на слизистой оболочке правого верхнедолевого бронха

\section{Результаты и обсуждение}

Методом спирографии исследовали ФВД у 70 пациентов с ММ без сопутствующего бронхолегочного заболевания. У $1 / 2$ больных (35 человек) нарушений ВФЛ выявлено не было (пациенты из 1-й и 2-й группы с длительностью заболевания - 1-2 года и невысокой секрецией сывороточного М-компонента). У 35 пациентов с высокой секрецией сывороточного парапротеина и / или с почечной недостаточностью были выявлены умеренные нарушения ВФЛ: у 10 больных по рестриктивному и у 25 по смешанному типам. Снижение жизненной емкости легких диагностировано у всех 35 больных $(68,4 \pm 2,0$ \% долж.). У 25 пациентов отмечено умеренное снижение объема форсированно-

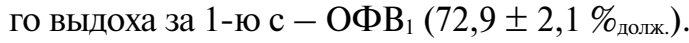

У $50 \%$ больных ММ стадии IIIA (2-я группа) и у $60 \%$ - с ХПН (3-я группа) при проведении ФБС диагностирован 2-сторонний диффузный атрофический эндобронхит (40 \% от общего числа пациентов с ММ).

Эндобронхиальная биопсия выполнена 10 пациентам 1-й группы, 10 больным - 2-й и 5 больным 3-й группы. У больных 2-й и 3-й группы при гистологическом исследовании биоптатов определяли отек, атрофию слизистой оболочки бронхов, у части больных под базальной мембраной - лимфоцитарную и плазмоклеточную инфильтрацию разной степени выраженности. У больных 2-й и 3-й группы в некоторых сосудах микроциркуляторного русла отмечалось скопление белковых масс, более выраженное при ХПН.

Эндобронхиальная ЛДФ проведена 30 больным ММ (по 10 человек из каждой группы). Метод ЛДФ заключается в зондировании ткани лазерным излучением и последующей обработке отраженного от ткани излучения в соответствии с допплеровским эффектом. Амплитуда сигнала формируется в результате отражения излучения от эритроцитов, движущихся с различной скоростью и по-разному количественно распределенных в артериолах, капиллярах, венулах и артериоло-венулярных анастомозах. [13]. При ММ нарушение микрогемоциркуляции в легких и в слизистой оболочке бронхов обусловлено повышенной вязкостью крови и анемическим синдромом. Чтобы максимально снизить влияние анемии на показатели ПМ, у больных ММ 2-й и 3-й группы анемический синдром был купирован до проведения исследования. Уровень гемоглобина при проведении ЛДФ был $\geq 100$ г / л, содержание эритроцитов $\geq 3 \times 10^{12} /$ л. Таким образом, попытались установить снижение скорости движения эритроцитов в микрососудах, что при ММ обусловлено прежде всего синдромом повышенной вязкости крови. Показатель параметра микрогемоциркуляции (ПМ), характеризующий состояние перфузии тканей, достоверно уменьшался по мере прогрессирования ММ (табл. 1). Установлена достоверная обратная корреляционная связь между повышением уровня сывороточного парапротеина и снижением ПМ $(r=-0,8 ; p<0,01)$, между длительностью заболевания ММ и снижени- 
ем ПМ $(r=-0,64 ; p<0,05)$, между повышением уровня креатинина крови и снижением ПМ ( $r=-0,5$; $p<0,05)$. Значения среднего квадратичного отклонения ПМ, отражающего сохранность механизмов регуляции кровотока в микроциркуляторном русле, у больных 1-й и 2-й группы не имели достоверных различий в сравнении с группой контроля и уменьшались в 3-й группе (табл. 1). Коэффициент вариации, характеризующий зависимость перфузии ткани от модуляции кровотока, увеличивался в процессе прогрессирования опухоли и во всех группах значительно превышал контрольное значение (табл. 1).

Диагностировано снижение колебаний в эндотелиальном диапазоне у больных 2-й и 3-й группы, что свидетельствует об эндотелиальной дисфункции и снижении выработки оксида азота у больных ММ на поздних этапах опухолевой прогрессии (табл. 1). Снижение эндотелиальных колебаний коррелировало со стадией заболевания $(r=-0,72 ; p<0,01)$, уровнем парапротеина $(r=-0,56 ; p<0,05)$ и креатинина крови $(r=-0,56 ; p<0,05)$. Можно предположить, что при ММ значимыми факторами развития эндотелиальной дисфункции являются парапротеинемия, диспротеинемия и уремическая интоксикация.

У больных ММ не выявлено достоверного изменения колебаний в нейрогенном (обусловленном симпатическими влияниями на гладкомышечные клетки артериол и артериоловенулярных анастомозов), миогенном (характеризующем состояние мышечного тонуса прекапилляров), дыхательном (характеризующем отток крови в венулы) диапазонах (табл. 1).

$\mathrm{A}_{\mathrm{c}}$ у больных ММ уменьшались в процессе опухолевой прогрессии, что свидетельствует о снижении притока артериальной крови в микроциркуляторное русло вследствие развития синдрома повышенной вязкости крови (табл. 1). По данным эндобронхиальной биопсии, у больных 3-й группы белковые стазы выражены в большей степени, чем у пациентов 2-й группы, поэтому при наличии ХПН зарегистрированы наименьшие показатели амплитуд колебаний в данном диапазоне. Выявлены обратные корреляционные связи между снижением колебаний в кардиальном диапазоне и уровнем парапротеина крови $(r=-0,7 ; p<0,01)$, длительностью заболевания ММ $(r=-0,58 ; p<0,05)$, уровнем креатинина крови $(r=-0,5 ; p<0,05)$.
Очевидно, что аналогичные нарушения микрогемоциркуляции имеют место и в легких. Так, у значительного количества больных 2-й и 3-й группы при проведении рентгенологического исследования были выявлены усиление и деформация легочного рисунка, что обусловлено застоем крови в мелких сосудах с развитием пневмосклероза, т. к. в связи с повышенной вязкостью плазмы замедляется кровоток в системе легочных капилляров.

Нарушение микрогемоциркуляции способствует ухудшению трофики тканей, развитию тканевой гипоксии, угнетению обмена веществ в клетках слизистой оболочки бронхов. Вследствие этого происходят атрофические изменения слизистой бронхов, диагностированные у 40 \% больных ММ при ФБС.

Изучалось влияние цитостатической терапии на показатели микрогемоциркуляции у больных ММ. В тех случаях, когда после проведения цитостатического лечения удавалось достичь полной или частичной ремиссии заболевания, пациентам ММ повторно проводили эндобронхиальную ЛДФ. У всех отмечалось увеличение показателей ПМ, но ни в одном случае показатели ПМ полностью не нормализовались. Отмечалось улучшение $\mathrm{A}_{\ni}$ и $\mathrm{A}_{\mathrm{c}}$ (табл. 2). Сохранение нарушений эндобронхиальной микрогемоциркуляции у больных ММ после достижения полной или частичной ремиссии объясняется многофакторностью нарушений функционирования микроциркуляторного русла. Кроме синдрома повышенной вязкости крови и анемии на снижение показателей микрогемоциркуляции оказывают влияние нарушения тромбоцитарного и плазменного гемостаза, состояние эндотелия сосудов, регуляция тканевого сосудистого тонуса, показатели рН крови и давления кислорода $\left(\mathrm{pO}_{2}\right)$, гормональный фон и многие другие факторы [13]. У большинства больных ММ при достижении частичной ремиссии сохраняется минимальная продукция моноклонального иммуноглобулина.

Другой важной причиной заболеваемости респираторными инфекциями при ММ является нарушение сократительной способности диафрагмы. При ультразвуковом исследовании диафрагмы у пациентов с выраженным остеодеструктивным процессом грудной клетки (2-я группа) и почечной недостаточностью (3-я группа) зарегистрировано значительное

Таблица 1
Сравнительная характеристика показателей ЛДФ в проксимальных отделах бронхов у здоровых лиц, и больных ММ

\begin{tabular}{|c|c|c|c|c|}
\hline Показатели & Контрольная группа $(n=30)$ & 1 -я группа $(n=10)$ & 2-я группа $(n=10)$ & 3-я группа $(n=10)$ \\
\hline ПМ, ПЕ & $82,3 \pm 5,3$ & $69,6 \pm 5,0$ & $42,51 \pm 3,10^{\star * *}$ & $17,85 \pm 2,20^{* * *}$ \\
\hline$\sigma$, ПЕ & $10,7 \pm 0,5$ & $10,0 \pm 0,4$ & $12,22 \pm 2,00$ & $5,85 \pm 0,20^{* * *}$ \\
\hline$K v, \%$ & $13,8 \pm 1,2$ & $12,6 \pm 1,1$ & $26,0 \pm 3,0^{* * *}$ & $32,75 \pm 4,70^{* * *}$ \\
\hline $\mathrm{A}_{3}, \mathrm{ME}$ & $3,9 \pm 0,4$ & $3,7 \pm 0,2$ & $2,50 \pm 0,13^{* *}$ & $2,30 \pm 0,18^{* * *}$ \\
\hline$A_{H}$, ПE & $3,2 \pm 0,7$ & $2,9 \pm 0,5$ & $2,70 \pm 0,26$ & $2,00 \pm 0,16$ \\
\hline$A_{M}, \Pi E$ & $3,6 \pm 0,8$ & $3,4 \pm 0,5$ & $5,4 \pm 0,8$ & $2,77 \pm 0,20$ \\
\hline$A_{A}, \Pi E$ & $3,7 \pm 0,5$ & $3,7 \pm 0,4$ & $4,4 \pm 0,5$ & $2,63 \pm 0,16$ \\
\hline$A_{c}, \Pi E$ & $3,4 \pm 0,4$ & $3,2 \pm 0,3$ & $2,50 \pm 0,13^{*}$ & $1,46 \pm 0,13^{* * *}$ \\
\hline
\end{tabular}

Примечание: ПМ - параметр микрогемоциркуляции, $\sigma$ - среднее квадратичное отклонение ПМ; Кv - коэффициент вариации; ${ }^{*}-p<0,05 ;{ }^{* *}-p<0,01 ;{ }^{* * \star}-p<0,001$. 
Таблица 2

ЛДФ-показатели в проксимальных отделах бронхов больных ММ с высоким исходным содержанием парапротеина в крови после достижсения полной или частичной ремиссии заболевания $(M \pm m)$

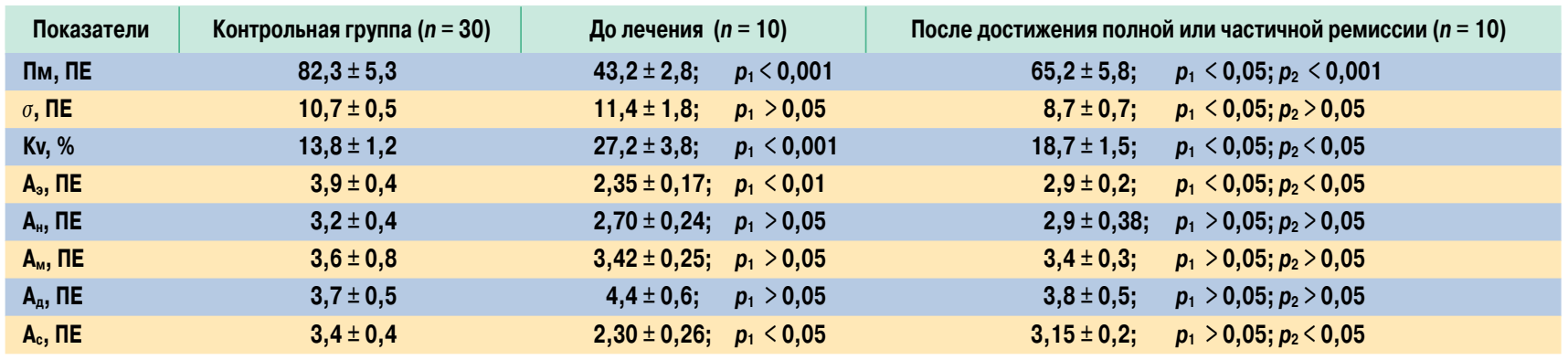

Примечание: $p_{1}$ - достоверность различий по сравнению с контрольной группой; $p_{2}$ - достоверность различия между показателями ЛДФ, до и после достижения ремиссии.

снижение ее экскурсии при спокойном и форсированном дыхании (табл. 3).

У больных 1-й группы показатель $\mathrm{pO}_{2}(86,5 \pm$ 5,0 мм рт. ст.) не отличался от аналогичного в контрольной группе $\left(88,0 \pm 4,0\right.$ мм рт. ст.). Снижение $\mathrm{pO}_{2}$ у больных 2-й группы $(78,5 \pm 2,5$ мм рт. ст.; $p<0,05)$ и 3-й группы $(66,0 \pm 3,2$ мм рт. ст.; $p<0,001)$ объясняется нарушением вентиляционной функции легких. У больных ММ, осложнившейся ХПН, диагностирован ацидоз (показатель рН крови у больных III группы в среднем составил 7,24 $\pm 0,03)$.

ЭХОКГ и ИДКГ были проведены 50 больным ММ в возрасте от 33 до 70 лет, без сопутствующих ХОБЛ, артериальной гипертензии и пороков сердца (12 больных из 1-й, 27 - из 2-й и 11 - из 3-й группы). Легочная гипертензия (ЛГ) была диагностирована у 26 больных (52 \%). Показатель ДЛА ср у этих больных в среднем составил $23 \pm 0,9$ мм рт. ст. Все пациенты с ЛГ относились ко 2-й и 3-й группе (17 и 9 человек соответственно). У больных ММ с повышенным ДЛА ср (по данным эхокардиографических исследований) был выраженный деструктивный процесс в костях, в т. ч. в ребрах, грудине, грудном отделе позвоночника. У части из них отмечена значительная деформация грудной клетки. У больных с ХПН отмечены наиболее высокие показатели ДЛА пациентов (48 \%) показатель ДЛА не превышал 20 мм рт. ст. Из них у 17 человек он находился в пределах 9-16 мм рт. ст. и у 7 пациентов в пределах 17-20 мм рт. ст.

Проведено морфологическое исследование легких, бронхов, плевры 65 умерших от ММ. У 38 пациентов (58 \%) диагностирован парапротеиноз легких: белковые массы, заполняющие легочные альвеолы, создавали картину белкового отека легких, импрегнировали утолщенные, гиалинизированные межальвеолярные перегородки и заполняли сосуды различного калибра. Проявления амилоидоза в данном исследовании выявлены только у 9 пациентов (13,8 \% всех умерших), у которых обнаруживалось отложение белковых масс в межальвеолярных пространствах, периваскулярно, перибронхиально, а также в стенках кровеносных сосудов. У 26 человек (40 \%) имела место лимфоидная и плазмоклеточная инфильтрация в виде тяжей или узлов в межальвеолярных перегородках, по ходу сосудистого адвентиция, в подслизистой оболочке бронхов и в перибронхиальных пространствах. У умерших с ХПН (52 пациента - 80\%) диагностировали нефрогенный отек легких (80\%), уремический пневмонит (28 \%), кальциноз (25\%). Межальвеолярные перегородки были утолщены изза инфильтрации плазматическими клетками и / или лимфоцитами, а у умерших с ХПН - еще и из-за отека. Уменьшение площади части альвеол у больных ММ связано с утолщением и отеком межальвеоллярных перегородок, проявлениями парапротеиноза легких, изменениями со стороны бронхов и сосудов. У умерших больных с ХПН изменения в пораженных альвеолах были выражены в большей степени. В сохранившихся участках легкого имело место компенсаторное расширение альвеол. Эмфизема легких (диффузная и компенсаторная локализованная) и пневмосклероз диагностированы у 78,5 \% умерших от ММ, миеломатозное поражение плевры - у 6,5 \%.

У больных ММ в стадии IIIA и при наличии почечной недостаточности в диафрагме отмечено преобладание миоцитов средних размеров (площадь поперечного сечения 608,9 \pm 20 мкм $^{2} ; 45,5 \pm 0,5 \%$ ), но диагностировано увеличение миоцитов большого $\left(1920 \pm 34\right.$ мкм $\left.^{2} ; 17,3 \pm 0,3 \%\right)$ и малого (287 \pm 14 мкм $^{2}$; $35,5 \pm 0,5 \%$ ) размеров. У этих же больных выявлено значительное разрастание стромы вокруг сосудов, в межмышечном пространстве $(27,5 \pm 0,85 \%)$ и большие участки липоматоза. Важную роль в развитии дистрофии поперечнополосатой мускулатуры диафрагмы играют ее лимфоидная и плазмоклеточная ин-

Таблица 3

Показатели ультразвукового сканирования диафрагмы у больных ММ

\begin{tabular}{|c|c|c|c|c|}
\hline Показатель & Контрольная группа ( $n=30)$ & 1 -я группа ( $n=12)$ & 2-я группа ( $n=27)$ & 3-я группа ( $n=11)$ \\
\hline ТД, мм & $5,8 \pm 0,5$ & $5,8 \pm 0,3$ & $5,7 \pm 0,2$ & $5,70 \pm 0,18$ \\
\hline ЭД, мм & $20,60 \pm 1,36$ & $19,0 \pm 1,7$ & $10,28 \pm 0,70^{*}$ & $9,75 \pm 0,35^{\star}$ \\
\hline ЭД & $80,2 \pm 4,5$ & $70,1 \pm 5,0$ & $24,0 \pm 1,4^{*}$ & $22,0 \pm 0,8^{*}$ \\
\hline
\end{tabular}

Примечание: ТД - толщина диафрагмы; ЭД - экскурсия диафрагмы при спокойном дыхании; ЭД - экскурсия диафрагмы при форсированном дыхании; * - $<_{<}$0,001. 
фильтрация, белковые стазы в мелких сосудах, приводящие к нарушению микроциркуляции, при наличии ХПН - уремическое поражение и отек диафрагмы.

\section{Заключение}

Проанализированы и сопоставлены показатели вентиляционной функции легких с морфологическими изменениями в легких и бронхах у больных ММ. У пациентов 2-й группы (стадия IIIA) диагностировались парапротеиноз легких, лимфоидная и плазмоклеточная инфильтрация легких и бронхов, реже амилоидоз легких и миеломатозное поражение плевры с развитием экссудативного плеврита, была значительно снижена микрогемоциркуляция вследствие гипервискозности плазмы и наличия белковых стазов в сосудах микроциркуляторного русла. Грудная клетка у большинства таких больных деформирована, следовательно, нарушена экскурсия легких при дыхании. У пациентов с выраженным деструктивным процессом в костях грудной клетки развиваются атрофические изменения в диафрагме вследствие ее миеломатозного поражения и нарушения сократительной способности. Эта патология оказывает значительное влияние на снижение вентиляционной функции легких у пациентов 2-й группы. Повышенная вязкость плазмы, наличие белковых внутрисосудистых стазов, повышенная фильтрация белка в альвеолах, нарушение кровообращения в легких приводят к лизису эластического каркаса легких [8]. Развитию рестриктивного типа дыхательной недостаточности может способствовать специфическая плазмоклеточная и лимфоидная инфильтрация легких. С прогрессированием хронической почечной недостаточности (3-я группа) присоединяются уремические поражения - уремический пневмонит и кальциноз. Эти морфологические изменения не имеют характерных клинических проявлений, но могут оказать значительное влияние на нарушение вентиляционной функции легких. Поэтому показатели вентиляционной функции легких у больных 3-й группы продолжают снижаться. Ни у одного пациента в данном исследовании не диагностирован интрабронхиальный рост миеломы, поэтому снижение ОФВ 1 следует объяснить отеком, специфической плазмоклеточной и лимфоидной инфильтрацией, склеротическими изменениями слизистой оболочки бронхов, при присоединении ХПН уремическими поражениями - нефрогенным отеком и уремическим бронхитом. Можно сделать заключение о том, что развитию легочной гипертензии у 52 \% больных ММ способствуют: 1) гипоксемия вследствие нарушения экскурсии грудной клетки и диафрагмы, тяжелого течения воспалительных и специфических парапротеинемических и уремических процессов в легких, нарушения реологии крови в сосудах малого круга кровообращения; 2) дисфункция эндотелия; 3) дистрофия миокарда; 4) ацидоз при наличии почечной недостаточности.

Выявленные клинические, морфологические и функциональные изменения бронхолегочной системы, наряду с выраженным вторичным иммуноде- фицитом, способствуют возникновению бронхолегочных инфекций при ММ, их тяжелому и затяжному течению.

\section{Литература}

1. Вотякова О.М., Демина Е.А. Множественная миелома. В кн.: Волкова М.А. (ред.). Клиническая онкогематология, 2-е изд. М.: Медицина; 2007. 847-871.

2. Вотякова О.М., Османов Д.Ш., Демина Е.А. и др. Использование велкейда при множественной миеломе. Tep. арх. 2007; 7: 70-73.

3. Змачинский В.А., Усс А.Л., Миланович Н.Ф. и др. Лечение множественной миеломы. Опыт Белорусского центра гематологии и трансплантации костного мозга. Гематол. и трансфузиол. 2005; 6: 45-48.

4. Менделеева Л.П., Покровская Л.П. Миеломная болезнь. В кн.: Савченко В.Г. (ред.). Программное лечение лейкозов. М.; 2008; т. 1: 343-399.

5. Бессмельцев С.С., Абдулкадыров К.М. Множественная миелома. СПб.: Диалект; 2004.

6. Чучалин А.Г. Респираторная медицина: Руководство для врачей. М.: ГЭОТАР-Медиа; 2007; т. 1-2.

7. Андреева Н.Е, Балакирева Т.В. Парапротеинемические гемобластозы. В кн.: Воробьев А.И. (ред.). Руководство по гематологии, 3-е изд. М.: Ньюдиамед; 2003; т. 2: 151-184.

8. Войно-Ясенецкая О.В. Легочно-альвеолярный парапротеиноз у больных миеломной болезнью. Пробл. гематол. $1975 ; 10: 32-35$.

9. Durie B.G.M., Salmon S.E. A clinical staging system for multiple myeloma: Correlation of measured myeloma cell mass with presenting clinical features, response to treatment, and survival. Cancer (Philad.)1975; 36 (3): 842-854.

10. Пат. 2281684 РФ. Способ диагностики микроциркуляторных расстройств в слизистой оболочке бронхов у больных бронхиальной астмой / Ландышев Ю.С., Красавина Н.П., Кравец Е.С. и др.; заявитель и патентообладатель Амурская государственная медицинская академия. № 2005117772/14; заявл. 08.06.05; опубл. 20.08.06, Бюл. № 23 (ІІ ч). С. 4.

11. Авдеев С.Н. Легочная гипертензия при хронических респираторных заболеваниях. В кн.: Чучалин А.Г. (ред.). Пульмонология: Нац. руководство. М.: ГЭОТАРМедиа; 2009. 599-619.

12. Пат. 2140768 РФ. Способ определения толщины и экскурсии диафрагмы с помощью ультразвукового сканирования для диагностики утомления диафрагмальной мышцы / Сивякова О.Н., Мажарова О.А.; заявитель и патентообладатель Амурская государственная медицинская академия. № 96113301/14; заявл. 04.07.96; опубл. 10.11.99, Бюл. № 31 (ІІ ч). С. 247.

13. Крупаткин А.И., Сидоров В.В. Лазерная допплеровская флоуметрия микроциркуляции крови. М.: Медицина; 2005.

\section{Информация об авторах}

Войцеховский Валерий Владимирович - д. м. н., доцент кафедры госпитальной терапии Амурской государственной медицинской академии; тел.: (4162) 42-94-97; e-mail: voiceh-67@mail.ru

Ландышев Юрий Сергеевич - д. м. Н., проф., зав. кафедрой госпитальной терапии Амурской государственной медицинской академии; тел.: (4162) 42-94-19; e-mail: land8@mail.ru

Григоренко Алексей Александрович - д. м. н., проф., зав. кафедрой патологической анатомии Амурской государственной медицинской академии; тел.: (4162) 44-52-21; e-mail: amursma@mail.ru

Поступила 04.02.09 () Коллектив авторов, 2010 удк 616-006.448-06:616.233/24-091 